\title{
Interactive numerical model of hydrometeorologic factors in Kola Bay
}

\author{
Izmail' Kantarzhi $^{*}$ and Aleksandr Anshakov ${ }^{\dagger}$ \\ Moscow State University of Civil Engineering, Yaroslavskoe shosse, 26, Moscow, 129337, Russia
}

\begin{abstract}
The structure of the developed interactive model of wind waves and currents for the construction area in the Kola Bay, Barents Sea is considered. The interaction between three modules of the developed model which based on the SWAN, ARTEMIS and COASTOX models is shown. The interactive model can be applied to get the statistical characteristics of waves and currents. The article presents an overview of the results of applying a chain of numerical models to determine the wave loads on the structures of the projected Center for the Construction of Large-capacity Marine Structures in the Kola Bay.
\end{abstract}

\section{Introduction}

The paper presents the developed numerical interactive model of currents and wind waves in the Kola Bay, Barents Sea, which was designed to simulate wave modes, currents and level changes in various synoptic situations and configurations of projected port structures.

The interactive model uses the 2D model of sea currents - COASTOX, as well as opensource wave models: spectral models of generation and transformation of wind waves, SWAN and WaveWatchIII, and the model of waves in the structure area, ARTEMIS. Brief description of the models SWAN, ARTEMIS, and COASTOX is provided.

The structure of the interactive model of wind waves and currents, information flows between its three modules based on the SWAN, ARTEMIS and COASTOX models are described in detail. The developed interactive model was used in the research of the Center for the Construction of Large-capacity Marine Structures (CCLMS). The determined by interactive model wave statistical characteristics in the key points of the project area are presented.

\section{Methods}

The climatic characteristics of wind waves in the specified points at the approach to the design area were determined by the spectral models of wind waves, SWAN and WaveWatchIII [1]. The WaveWatchIII model was used to simulate the formation and transformation of wind waves in the deep-water zone of the Barents Sea, and then, these data were transmitted to the SWAN model, suitable for modeling the wave processes in the coastal zone.

\footnotetext{
*kantardgi@yandex.ru

†anshakov.aleks.xx@yandex.ru
} 
Model SWAN, Technical University of Delft, distributed in internet, based on the balance equation of the wave action with sources and sinks [2,3]. The model describes the next wave processes: wind wave generation; propagation on the variable depth; shoaling by depth and current; refraction; diffraction; blocking and reflection of waves by opposite directional currents; passing through the flooded obstacles. This model is used in the research because there is its successful application in many engineering projects, as well as testing (verification) based on the relevant data of field measurements.

COASTOX is a model for simulation the coastal current fields generated by the combined effect of wind, deep-water gradient currents, tides, and wind waves $[4,5]$. The numerical module solves two-dimensional shallow water equations using the finite volume method on unstructured grids, including components describing the effects of bottom friction, wave radiation stresses, and horizontal turbulent mixing. Due to the universal structure of the equations, they can, in addition to coastal currents, under the appropriate boundary conditions and the disabled module of wave radiation stresses, describe a variety of long-wave processes, like the river flows, tidal wave transformation, storm surges, tsunami waves. The model has been used in various engineering problems to define the coastal currents. The conducted comparisons showed the acceptable accuracy and stability of the applied computational algorithm for complex bathymetry and coastal outlines. The following models of numerical solution of shallow water equations on unstructured grids participated in comparison with the COASTOX: Mike-11 "DHI" [6], ADCIRC USA [7, 8], and CMS-Flow Corps of Engineers of the US Army [9].

The disadvantages of these models include the inability to adequately describe the processes of diffraction in the hydraulic structure areas and in the internal waters of ports. Therefore, the ARTEMIS model, which considers the processes of diffraction and reflection of waves from obstacles, was used to simulate the wave regime in the coastal hydraulic structure's areas.

The ARTEMIS open access model [10] is based on an extended version of the mild slope equation (MSE) [11]. In the ARTEMIS code, the mild slope equations are solved numerically by the finite element method using a parallel computing algorithm. The model is part of the TELEMAC software package for calculating wave hydrodynamics problems [12], the open-source version of which is called TELEMACMAS CARET [13].

The choice of ARTEMIS as one of the three components of the interactive model developed in this project, along with its status as a freely distributed code, is also due to: successful testing of ARTEMIS for a large number of seaport projects, for example [14-17], as well as a set of tests, which, in comparison with the measurement data, are presented in the model documentation; the availability of both a version for regular waves and a spectral version of the model.

To calculate the wave characteristics on the approach to the Kola Bay from the Barents Sea and inside the Bay for the 30-year period from 1987 to 2016, a chain of wave spectral models - WaveWatchIII ver.5.16 and SWAN ver. 41.10 applied. The wind fields for the initiation of wave models were taken from the data of the NCEP-CFSR wind field reanalysis [18-20], obtained considering satellite observations.

Calculations of wind waves were carried out by three nested numerical grids. For the WaveWatchIII model, the first grid was used, which covers the Barents Sea from $66^{\circ}$ to $80^{\circ}$ North latitude and from $17^{\circ}$ to $55^{\circ}$ East longitude, the number of grid nodes is $229 \times 169$, the grid cell size is $10 \times 5 \mathrm{~min}$, or approximately $9.15 \mathrm{~km}$. The second and third grids (Fig. 1) were used for SWAN model. The cell size of each subsequent grid is 5 times smaller than the size of the previous grid. The second grid includes 106 to 76 nodes. The third grid covers the water area of the Kola Bay, the size of the third grid is 106 to 144 nodes. The second and third grids were used to simulate currents and sea level changes in the COASTOX model. There are shown (Fig.1) the boundaries of the calculation grids: the 
border of the second calculation grid - by red line, and the border of the third calculation grid - by green line.

To simulate the tides, change the level was set at the sea boundary of the numerical grid. The tide parameters were taken from the global tidal model TPXO7. 2 [21]. The dynamics of the level at the boundaries were calculated based on 13 tidal harmonics.

The bathymetry for the numerical grids was interpolated into nodes from the GEBCO topographic data available on the Internet on a 30 -second grid, and for the Kola Bay from digitized graphical nautical charts. For the water body of the port in the Kola Bay, the data of the bottom sounding with an echo sounder were used.

The wave parameters in the control points obtained using the SWAN and WaveWatchIII models were used to initialize the ARTEMIS refractive-diffraction model, which was used to calculate the wave elements of different repeatability in the water body of the object and near the berths.

The bathymetry of the middle knee of the Kola Bay, the design site and the boundary of the ARTEMIS calculation area are shown in Fig. 2. The black color shows the object's structures. Fig. 2 also shows the location of 15 control points SW1-5, S1-5, SE1-5, for which, according to the results of the SWAN model, the elements of waves of various repeatability were calculated using statistical methods.

In Fig.2 black color shows a configuration of the hydraulic structures of the object; and yellow color - border of the computational domain of ARTEMIS for waves of eastern (E) direction; red color - boundary of the computational region for western (W), southwestern (SW), southern (S), and South-Eastern (SE) directions. The points of presenting the results of the model SWAN are also shown in Fig.2. The waves in the parameters at points SW5, S3, and SE5 are used directly to initialize the ARTEMIS model. For the waves of the W and SW directions, the parameters from the point SW5 are used, for the S direction - from the point S3, and for the SE and E directions - from the point SE5.

The computational grid of the ARTEMIS model must be constructed, considering the limits of the numerical scheme. For a detailed calculated grid, it is necessary that the wavelength should include at least 7 grid nodes. For a rough computational grid, a less rigid condition of 4-5 nodes per wavelength is acceptable.

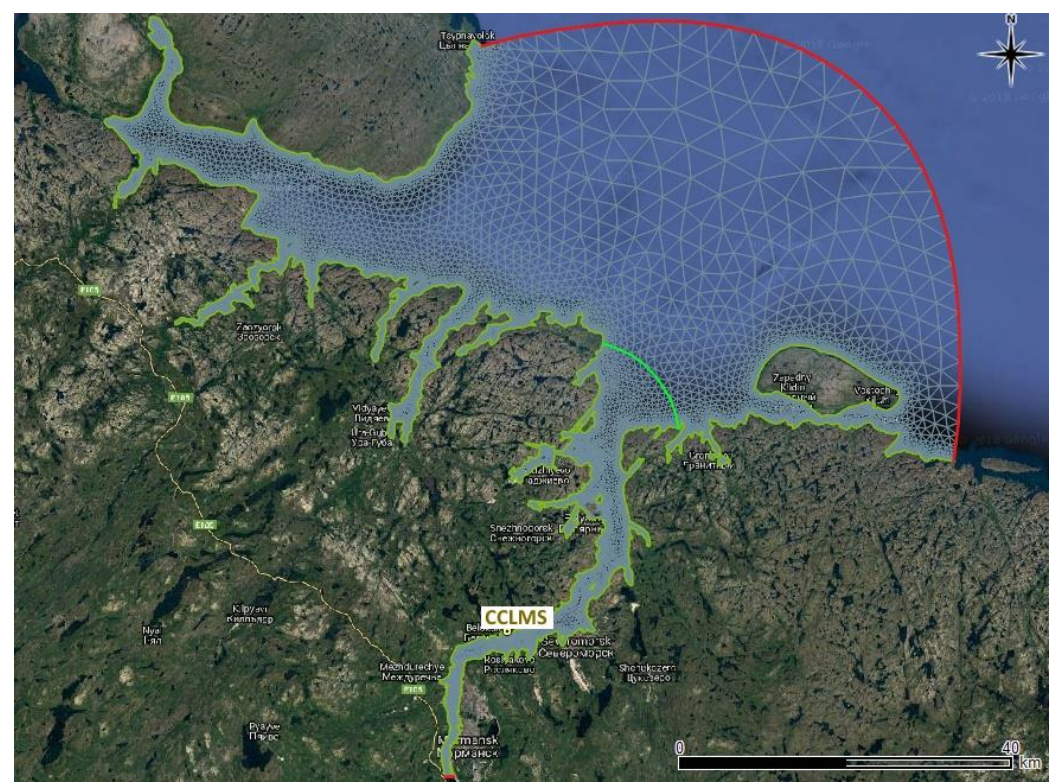

Fig. 1. The numerical grid of the SWAN and COASTOX models. UTM36 projection, EPSG: 32636 


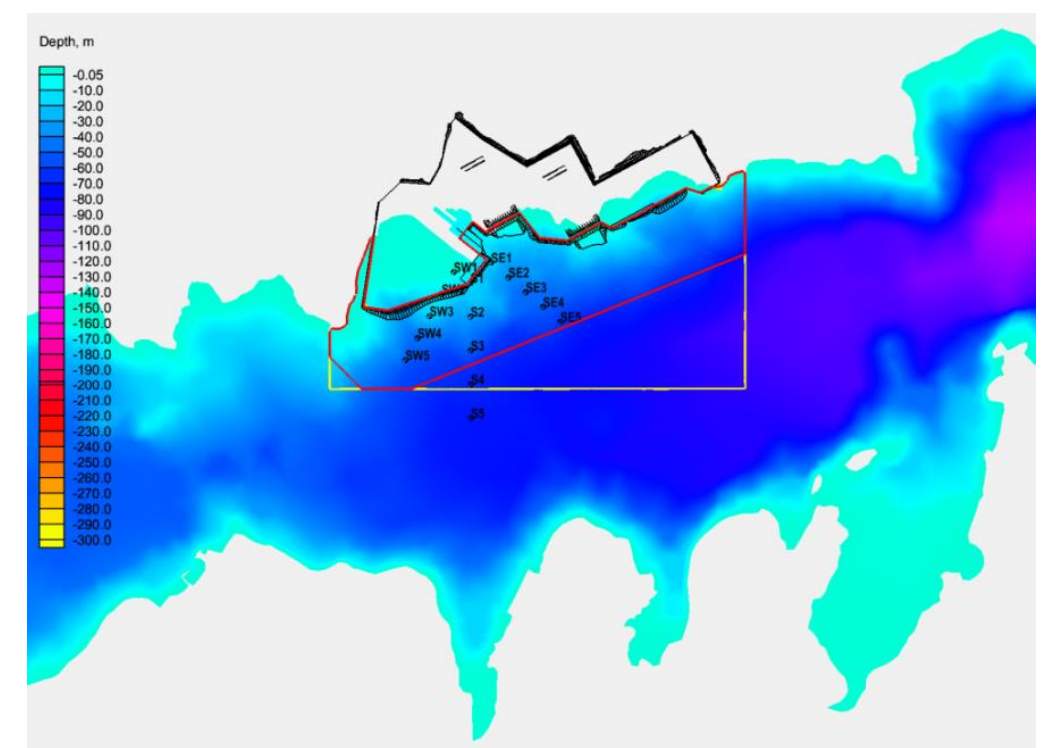

Fig. 2. Bathymetry of the Kola Bay in the study area of the CCLMS location, relative to the mean sea level. UTM36 projection, EPSG: 32636

The locally generated waves are quite short. The periods of these waves lead in the range of 2.5-4 s in accordance with the wave statistics. Which corresponds to wave lengths from 10 to $25 \mathrm{~m}$.

Universal grid for waves of all lengths, covering the entire water area of the CCLMS and suitable for modeling waves of all directions, will be very large with numbers of elements about 3000 000, which require large RAM resources and large expenditures of machine time.

Therefore, a compromise solution was chosen, and three grids were built: the mesh to the waves of the Eastern direction, the grid for the rest directions waves with a wavelength of $10 \mathrm{~m}$ and the mesh of the waves of the South and Southeast directions with a wavelength less than $10 \mathrm{~m}$.

The distribution of the wavelength in the region corresponding to a monochromatic wave with a period of 3 seconds (wavelength $\approx 14 \mathrm{~m}$ ) was taken as the basis for constructing the grid for waves of the E direction. Accordingly, the size of the grid cell, equal to the ratio $\lambda / 7$, varies in the range from $1.0 \mathrm{~m}$ in shallow water to $2.0 \mathrm{~m}$ at the maximal depth. The dimensions of the resulting grid are 891716 nodes and 1777789 elements.

To construct a grid for waves of other directions with a wavelength of more than $10 \mathrm{~m}$, the wavelength distribution corresponding to a wave with a period of 3 seconds was also taken. However, the orientation of the borders was different, and the area covered by the CCLMS water area was smaller. The dimensions of the resulting grid are 566944 nodes and 1128690 elements.

For S and SE waves of rare repeatability, the same study region with the same boundaries was selected and the wavelength distribution corresponding to a monochromatic wave with a period of 2 seconds (wavelength $6.24 \mathrm{~m}$ ) was taken. But for the construction of the grid, the less rigid condition $\lambda / 5$ was taken. Which gives the grid cell size at deep water around $1.25 \mathrm{~m}$. In shallow water, the size of the cells was limited by $1.0 \mathrm{~m}$. As a result, a grid of 1395966 nodes and 2784509 elements was constructed. 
The bathymetry of the calculated grids is constructed considering the configuration of the hydraulic structures of the CCLMS. The final bathymetry assigned to the mean sea level is shown in Fig. 3. The borders of the grids, wave-generating and reflecting, are also show. The reflection coefficient along the entire perimeter of the CCLMS (green line in Fig. 3) was assumed to be equal to 0.9 . The yellow color shows the wave-generating boundary of the calculated area for waves of the E direction, red color - the boundary of the calculated area for waves of the W, SW, S and SE directions, green color - the reflecting boundary. The control points for the output of the ARTEMIS model results are also shown.

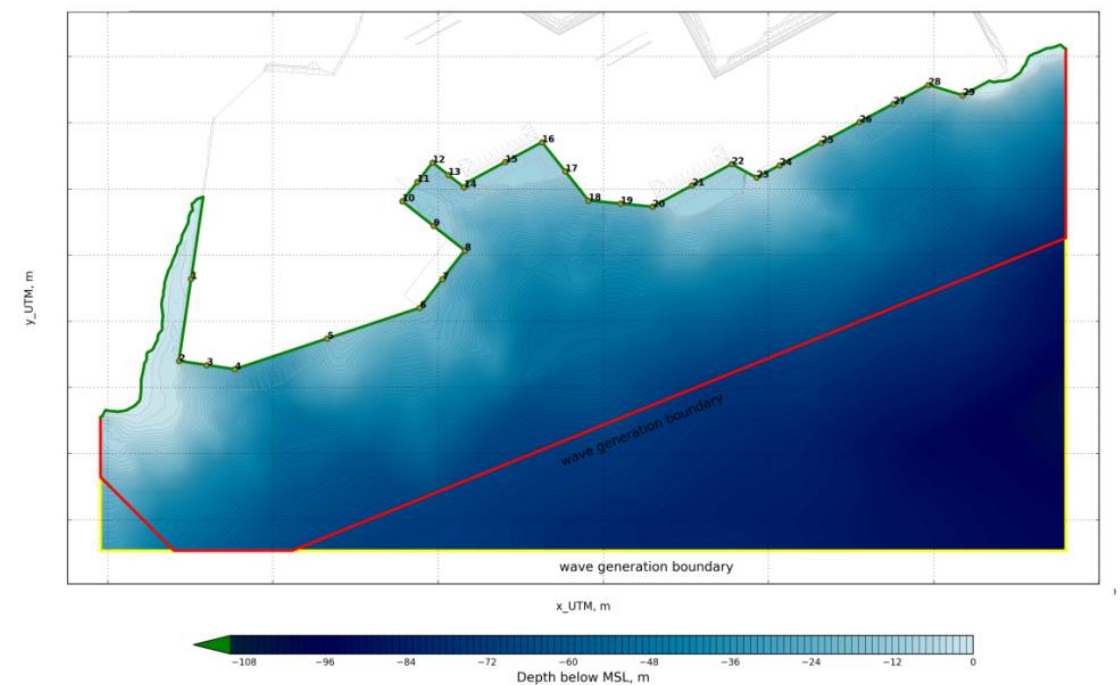

Fig. 3. Bathymetry on the calculated grid of the ARTEMIS model, relative to the mean sea level. UTM36 projection, EPSG: 32636

\section{Results and discussion}

The wave fields for the first, second, and third computational grids were calculated by the SWAN model for the entire period from 1987 to 2016. The calculation results were saved for the control points inside the bay near the projected port (Fig. 2). The data was analyzed to select the dates of the largest annual storms. At the analysis stage, it was noticed that large waves for these points come from various directions - West, Southwest, South, Southeast, and East. The statistical analysis of the waves for each of the five directions was therefore carried out.

To construct extreme wave fields of various repeatability, the wave elements (heights, directions, and periods) in the nodes of the numerical grid were selected, which correspond to the time points at which the wave height at point S3 is the maximal one for each year. Next, one used the so-called AMS approach (construction a distribution by annual maxima). For each point of the grid, it was obtained the Weibull distribution parameters, which were used to calculate the values of the heights of waves of rare repeatability. As an example, the fields of significant waves possible 1 time in 100 years for the Eastern direction of the wave approach for the water area of the Kola Bay are shown in Fig.4.

The wave parameters obtained by the SWAN model in the approach of the site were used as input data for the ARTEMIS model.

Using the ARTEMIS model, wave fields were modeled for all wave-prone areas of the planned CCLMS. The distribution of waves in the water area of the CCLMS, for a wave with a frequency of 1 time in 100 years of $1 \%$ repeatability, West direction (azimuth $260^{\circ}$ ) for the average long-term sea level is shown in Fig. 5. 
One of the advantages of the interactive model is the ability to change the configuration of structures, as well as the boundaries, such as the coefficients of reflection of waves from structures, changes in the reference sea levels, etc.

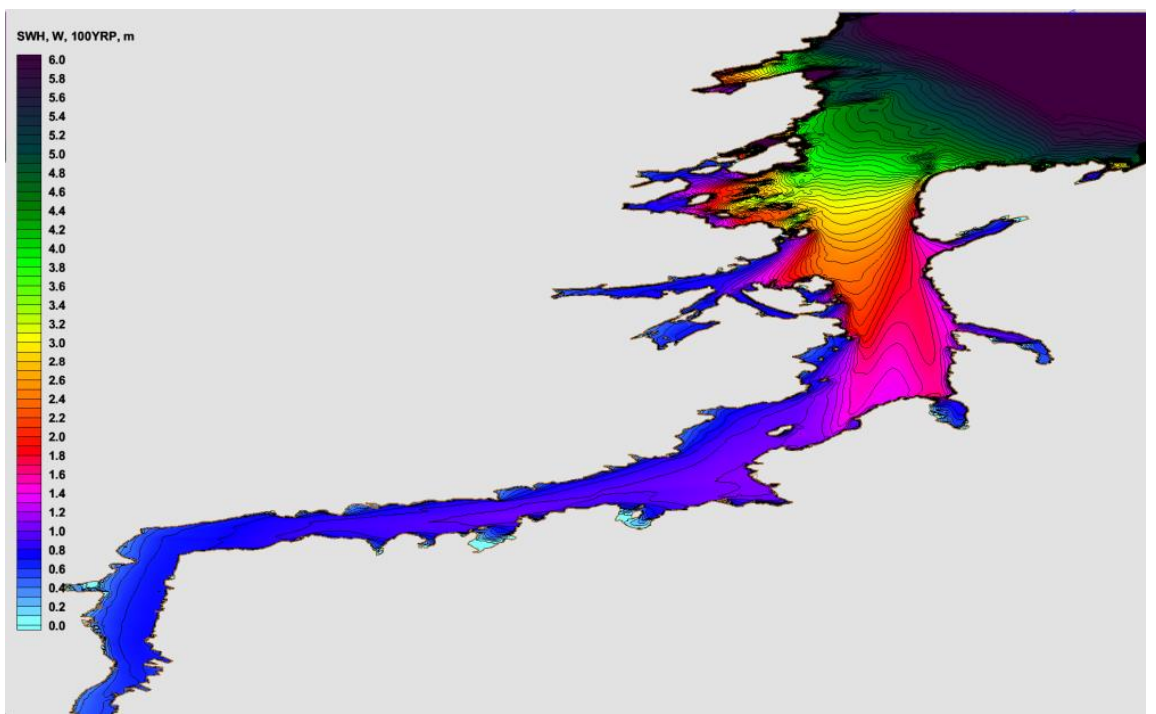

Fig. 4. The heights of significant waves possible 1 time in 100 years for the Eastern direction of the wave approach for the Kola Bay waters

The waves near the base of the gravity base structures (GBS) at the berth of the CCLMS are shown in Fig. 6. To get them, the calculation areas of the ARTEMIS model were redesigned, and additional control points were added. The changes made are described in more detail in [22].

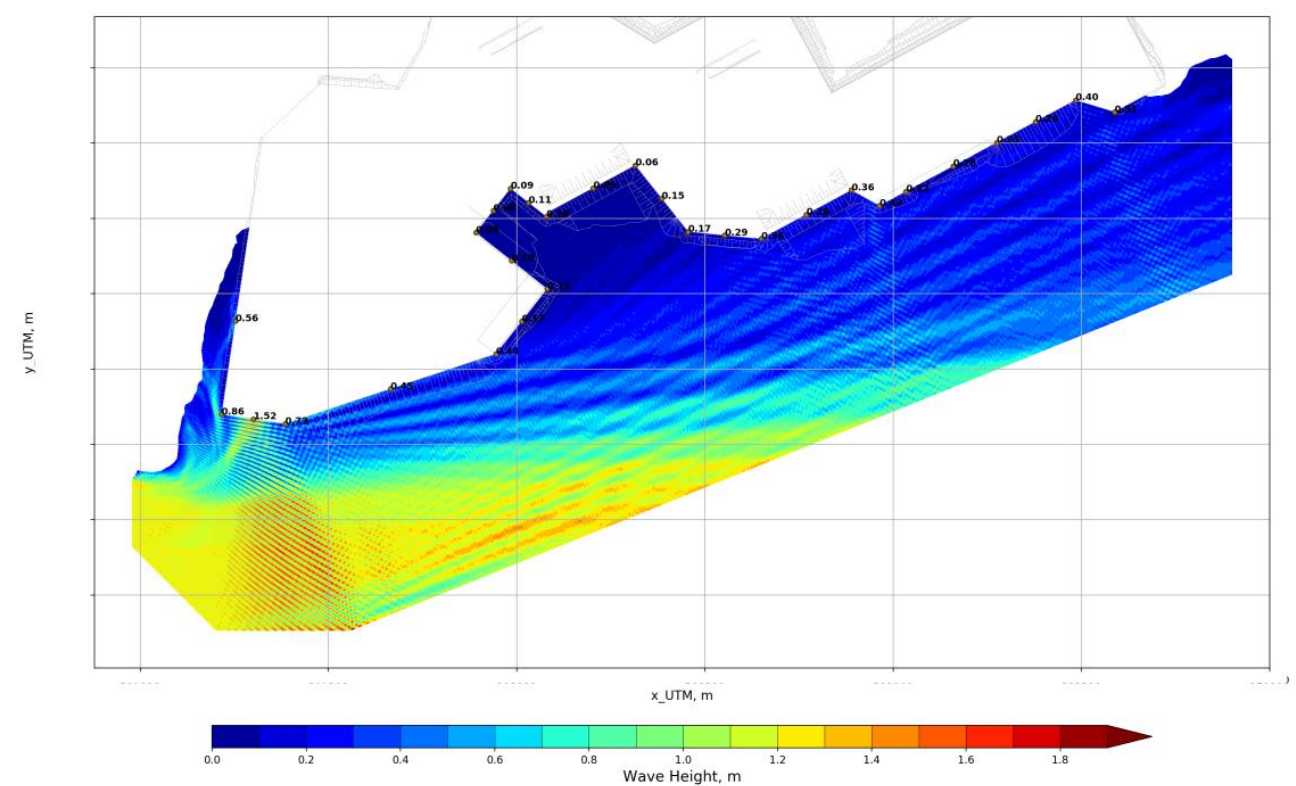

Fig. 5. Distribution of wave fields in the water area of the CCLMS, for a wave with a frequency of 1 time in 100 years of $1 \%$ repeatability, West direction (azimuth $260^{\circ}$ ) for the average long-term sea level 


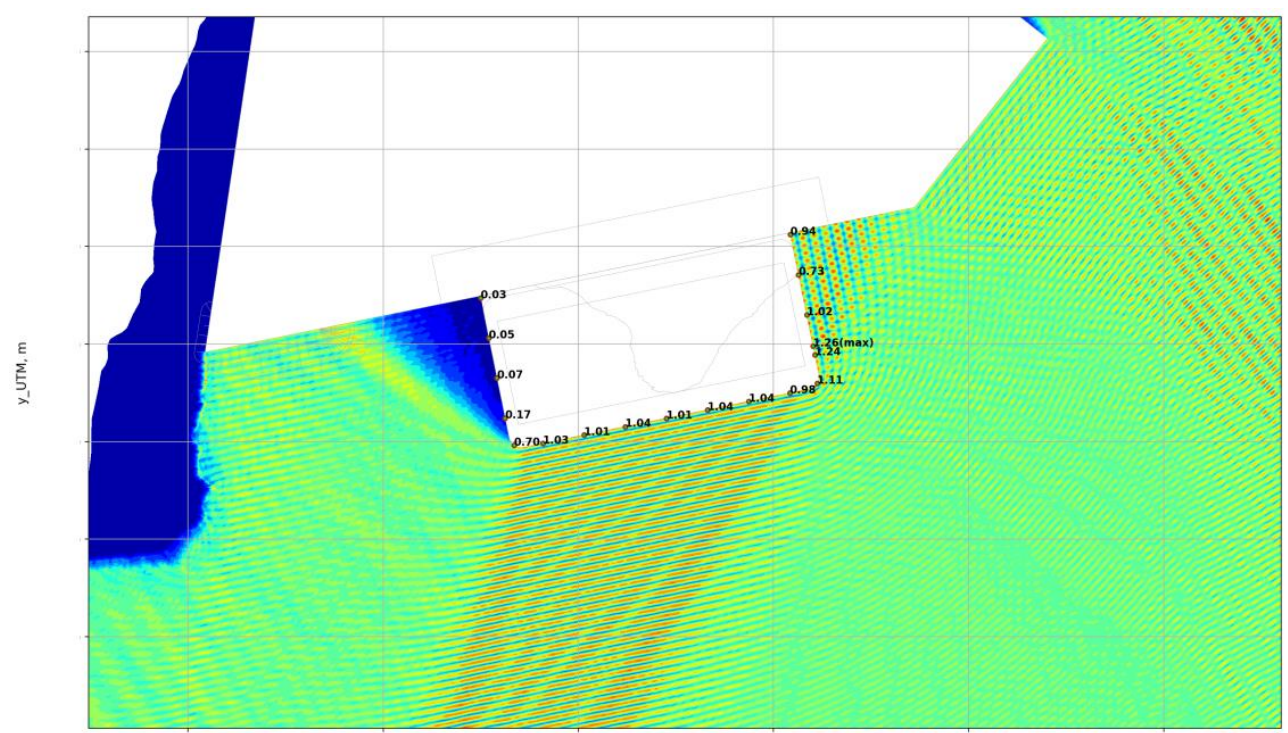

x_UTM, m

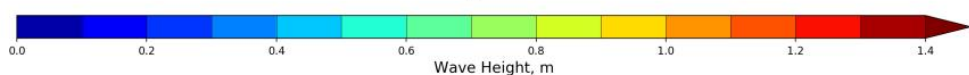

Fig. 6. Wave heights of the SE direction with a repeatability of 1 time in 50 years of $1 \%$ repeatability in the water area of the CCLMS near the GBS, for the reference sea level, minimal, $1 \%$ repeatability

Based on the initial data, the interactive model predicts the distribution of sea level and current velocities in the entire region for the selected period. As well as the sea level and current velocities obtained at the selected control points in the CCLMS area.

The simulation results are shown in Fig. 7 and 8. Fig. 7 shows the current field for the CCLMS water area with the old configuration of port facilities during the full tidal phase, 17.08.2015. Fig. 8 shows the current field for the CCLMS water area under the new configuration of port facilities during the full tidal phase, 17.08.2015.

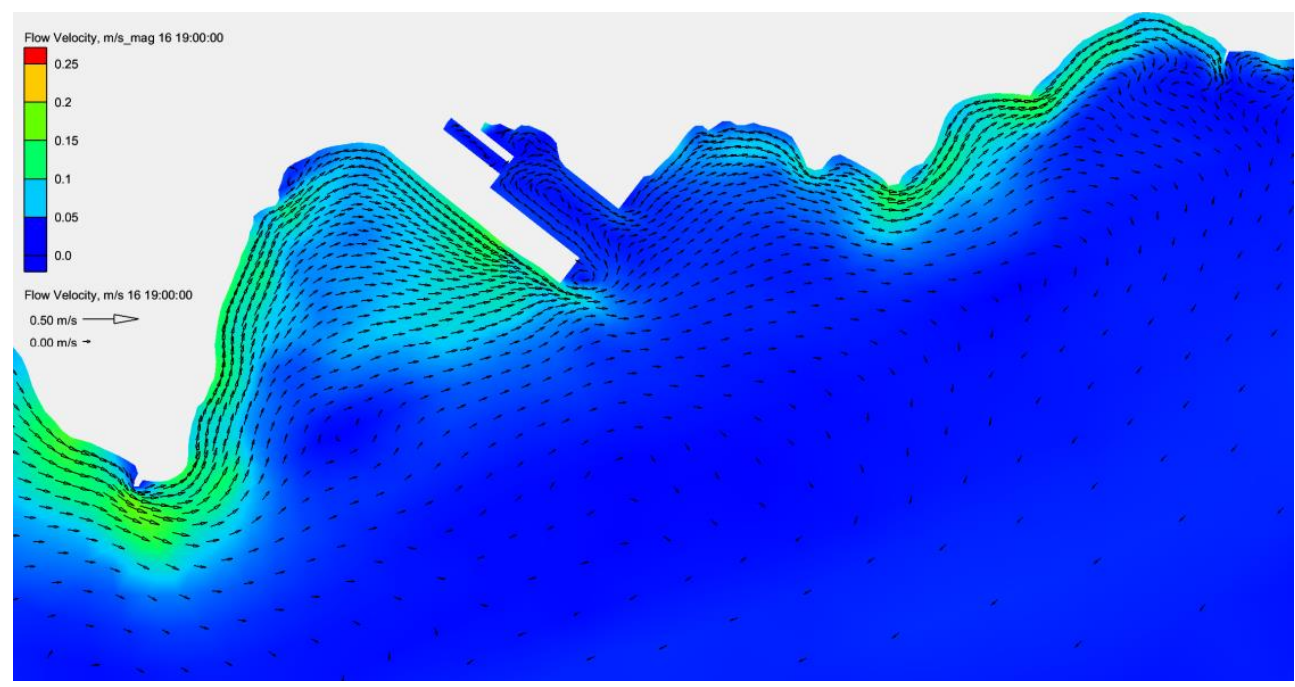

Fig. 7. Current pattent in the CCLMS water area (old configuration) during the full tidal phase, 17.08.2015. UTM36 projection, EPSG: 32636 


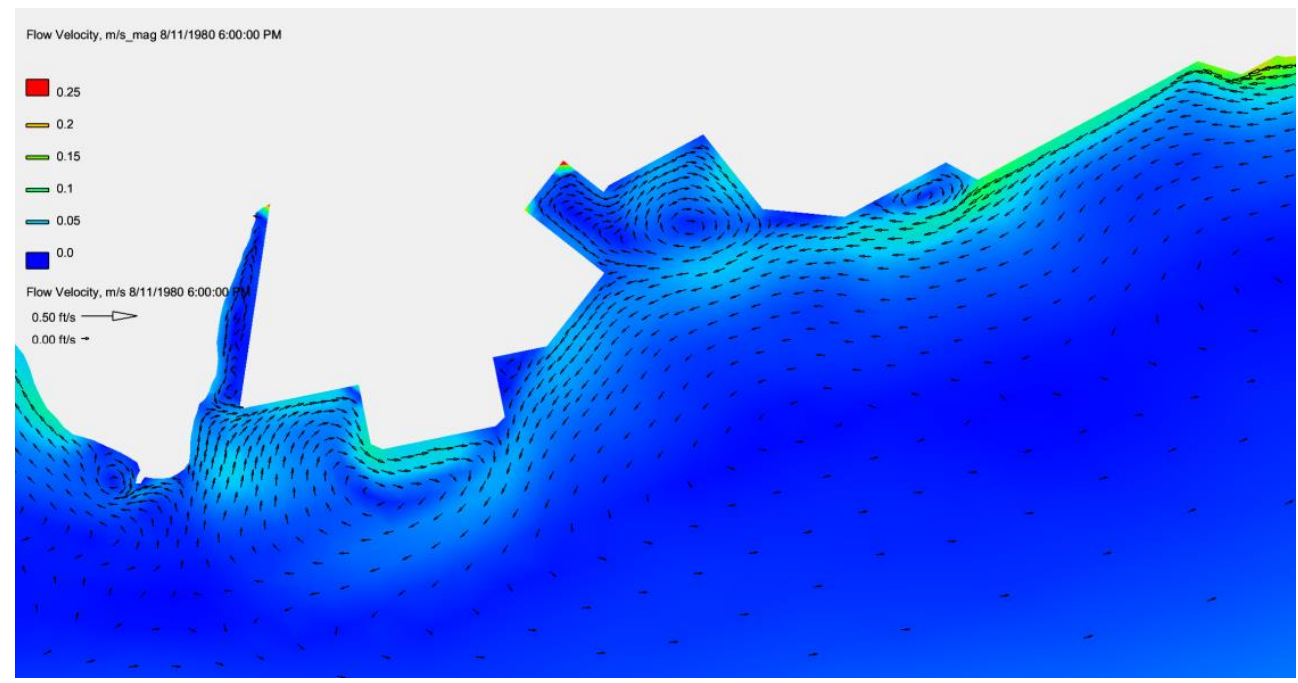

Fig. 8. Current pattent in the CCLMS water area (new configuration) during the full tidal phase, 17.08.2015. UTM36 projection, EPSG: 32636

\section{Conclusions}

The developed interactive model solves the problems of reliable prediction of the wave and current regime in the design of port facilities in Kola Bay. The model can be used for calculating the statistical characteristics of waves and currents, as well as for predictive calculations.

The structure of the developed interactive model of wind waves and currents for the design site in the Kola Bay is considered, and the interaction between its three calculation modules based on the SWAN, ARTEMIS and COASTOX models is shown. Interactive features of the model include the ability to change the input information on wind fields from the NCEP reanalysis. It is possible to extend the forecast period, for example, by increasing the number of past years or adding the last years to the estimated time series. The interactive model allows to change the boundary conditions, the characteristics of tides at the outer boundary of the computational domain or reanalysis data. One of the advantages of using an interactive model is the ability to change the configuration of port facilities. This paper illustrates this possibility to calculate the wave and current fields for different configurations of CCLMS structures.

The developed interactive model can be used to solve such problems as: determination the calculated parameters of waves at mooring structures to ensure safe conditions for ships; determination of the elements of waves at the structures to define the crest heights, wave loads, etc.; determination of currents to predict sediment transport.

This study was initiated particularly in the framework of the grant of the President of the Russian Federation (MK -3792.2021.4).

\section{References}

1. Tolman, User manual and system documentation of WAVEWATCH III $^{\mathrm{TM}}$ version 3.14. NOAA / NWS / NCEP / MMAB, Technical Note 276, 194 pp. (2009)

2. Holthuijsen L. H. Waves in oceanic and coastal waters, Cambridge University Press, (2007) 
3. SWAN team. Swan cycle III version 41.10AB, Scientific and Technical documentation, Delft University of Technology, Faculty of Civil Engineering and Geosciences (2017)

4. Kantarzhi, I., Zheleznyak, M., Demchenko, R., Dykyi, P., Kivva, S., Kolomiets, P., Sorokin, M.: Modeling of Nonlinear Hydrodynamics of the Coastal Areas of the Black Sea by the Chain of the Proprietary and Open Source Models. In: EGU General Assembly Conference Abstracts 16 (2014)

5. Zheleznyak, M., Kivva, S., Ievdin, I., Boyko, O., Kolomiets, P., Sorokin, M., Mikhalskyi, O., Gheorghiu, D.: Hydrological dispersion module of JRODOS: renewed chain of the emergency response models of radionuclide dispersion through watersheds and rivers. Radioprotection 51(HS 2), S129-S131 (2016)

6. DHI MIKE 21: 2D modelling of coast and sea, https://www.mikepoweredbydhi.com/products/mike-21

7. Westerink, J.J., Luettich, R.A., Feyen, J.C., Atkinson, J.H., Dawson, C., Roberts, H.J., Powell, M.D., Dunion, J.P., Kubatko, E.J., Pourtaheri, H.: A basin-to channel-scale unstructured grid hurricane storm surge model applied to southern Louisiana, Monthly weather review 136(3), pp. 833-864 (2008)

8. Kumar, V.S., Babu, V.R., Babu, M.T., Dhinakaran, G., Rajamanickam, G.V.: Assessment of storm surge disaster potential for the Andaman Islands. Journal of Coastal Research 24(sp2), pp. 171-177 (2008)

9. Reed, C.W., Brown, M.E., Sánchez, A., Wu, W., Buttolph, A.M., The coastal modeling system flow model (CMS-Flow): Past and Present, Journal of Coastal Research 1-6 (2011)

10. Aelbrecht, D., ARTEMIS 3.0: A finite element model for predicting wave agitation in coastal areas and harbours including dissipation, WIT Transactions on The Built Environment 30 (1997)

11. Berkhoff, J.C.W., Computation of combined refraction-diffraction, In: Proceedings of the 13th International Conference on Coastal Engineering, pp. 471-490. Vancouver, Canada, ASCE (1972)

12. Hervouet, J.M.: TELEMAC, a hydroinformatic system. LaHouilleBlanche3-4, pp. 2128, (1999)

13. Open TELEMAC-MASCARET. Artemis_documentation_6.2, Validation case studies 1-10, http://www.opentelemac.org/index.php/manuals/summary/9-artemis/148artemis-documentation-6-2 (2017)

14. Guillou, N. Chapalain, G.: Modeling penetration of tide-influenced waves in Le Havre harbor. Journal of Coastal Research 28(4), pp. 945-955 (2012)

15. Prodanovic, P.: Numerical simulation of coastal climate at a harbour site in the Great Lakes. In: Proceedings of the 21st TELEMAC-MASCARET User Conference 15-17 (2014)

16. Kantarzhi, I., Zheleznyak, M.: Laboratory and numerical study of waves in port water body, Civil Engineering Magazine 6, pp. 49-59 (2016)

17. Kantardgi, I.G., Zheleznyak, M.I., Anshakov, A.S., Numerical modeling of nonlinear hydrodynamics of the coastal areas, Magazine of Civil Engineering, 87(3), pp. 80-92 (2019)

18. Kalnay E., Kanamitsu M., Kistler R. et al. The NCEP/NCAR 40-year reanalysis project, Bull. Amer. Meteorol. Soc., Vol. 77 - No 3 - pp.437471, (1996) 
19. Saha S. et al. The NCEP climate forecast system reanalysis, Bull. Am. Meteorol. Soc., Vol. 91 - No. 8 - pp.1015-1057 (2010)

20. Saha S. et al. The NCEP Climate Forecast System Version 2, J. Climate, Vol. 27 pp.2185-2208 (2014)

21. Egbert G. D., Erofeeva S. Y., Efficient Inverse Modeling of Barotropic Ocean Tides, J. Atmos. Oceanic Technol., 19, 183204 (2002)

22. Izmail Kantarzhi, Aleksandr Anshakov, Numerical modeling of wind waves affected the marine structures in the Kola Bay, MATEC Web Conf. Volume 251, IPICSE-2018 - Article Number 04042 - pp.1-8 ( 2018). 